\title{
Finite element modeling of an alternating current electromagnetic weld pool support in full penetration laser beam welding of thick duplex stainless steel plates
}

Cite as: J. Laser Appl. 28, 022404 (2016); https://doi.org/10.2351/1.4943906

Submitted: 29 February 2016 . Accepted: 01 March 2016 . Published Online: 31 March 2016

Marcel Bachmann, Richard Kunze, Vjaceslav Avilov, and Michael Rethmeier
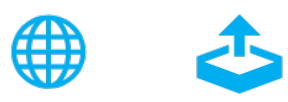

\section{ARTICLES YOU MAY BE INTERESTED IN}

Full penetration laser beam welding of thick duplex steel plates with electromagnetic weld pool support

Journal of Laser Applications 28, 022420 (2016); https://doi.org/10.2351/1.4944103

Magnetic stirring during laser welding of aluminum

Journal of Laser Applications 18, 28 (2006); https://doi.org/10.2351/1.2164477

A complete model of keyhole and melt pool dynamics to analyze instabilities and collapse during laser welding

Journal of Laser Applications 26, 042001 (2014); https://doi.org/10.2351/1.4886835

\section{Scilight}




\title{
Finite element modeling of an alternating current electromagnetic weld pool support in full penetration laser beam welding of thick duplex stainless steel plates
}

\author{
Marcel Bachmann \\ BAM Federal Institute for Materials Research and Testing, Unter den Eichen 87, 12205 Berlin, Germany
}

Richard Kunze and Vjaceslav Avilov

Technical University Berlin, Institute of Machine Tools and Factory Management, Pascalstraße 8-9, 10587 Berlin, Germany

\section{Michael Rethmeier}

BAM Federal Institute for Materials Research and Testing, Unter den Eichen 87, 12205 Berlin, Germany and Technical University Berlin, Institute of Machine Tools and Factory Management, Pascalstraße 8-9, 10587 Berlin, Germany

(Received 29 February 2016; accepted for publication 1 March 2016; published 31 March 2016)

\begin{abstract}
An electromagnetic weld pool support system for $20 \mathrm{~mm}$ thick duplex stainless steel AISI 2205 was investigated numerically and compared to experiments. In our former publications, it was shown how an alternating current (AC) magnetic field below the process zone directed perpendicular to the welding direction can induce vertically directed Lorentz forces. These can counteract the gravitational forces and allow for a suppression of material drop-out for austenitic stainless steels and aluminum alloys. In this investigation, we additionally adopted a steady-state complex magnetic permeability model for the consideration of the magnetic hysteresis behavior due to the ferritic characteristics of the material. The model was calibrated against the Jiles-Atherton model. The material model was also successfully tested against an experimental configuration before welding with a $30 \mathrm{~mm}$ diameter cylinder of austenitic stainless steel surrounded by duplex stainless steel. Thereby, the effects of the Curie temperature on the magnetic characteristics in the vicinity of the later welding zone were simulated. The welding process was modeled with a three-dimensional turbulent steady-state model including heat transfer and fluid dynamics as well as the electromagnetic field equations. Main physical effects, the thermo-capillary (Marangoni) convection at the weld pool boundaries, the natural convection due to gravity as well as latent heat of solid-liquid phase transitions at the phase boundaries were accounted for in the model. The feedback of the electromagnetic forces on the weld pool was described in terms of the electromagnetic-induced pressure. The finite element software COMSOL Multiphysics 4.2 was used in this investigation. It is shown that the gravity drop-out associated with the welding of $20 \mathrm{~mm}$ thick duplex stainless steel plates due to the hydrostatic pressure can be prevented by the application of AC magnetic fields between around 70 and $90 \mathrm{mT}$. The corresponding oscillation frequencies were between 1 and $10 \mathrm{kHz}$ and the electromagnetic $\mathrm{AC}$ powers were between 1 and $2.3 \mathrm{~kW}$. In the experiments, values of the electromagnetic AC power between 1.6 and $2.4 \mathrm{~kW}$ at oscillation frequencies between 1.2 and $2.5 \mathrm{kHz}$ were found to be optimal to avoid melt sagging or drop-out of melt in single pass full-penetration laser beam welding of 15 and $20 \mathrm{~mm}$ thick AISI 2205. () 2016 Laser Institute of America. [http://dx.doi.org/10.2351/1.4943906]
\end{abstract}

Key words: laser beam welding, electromagnetic weld pool support, duplex stainless steel, numerical simulation

\section{INTRODUCTION}

Today, typical laser beam welds have many advantages compared to traditional arc welding methods, e.g., the low heat input and the high welding velocity. ${ }^{1}$ In combination with the availability of industrial laser beam sources with steadily increasing output power and simultaneously higher beam quality, cost-effective single pass welding of thick metal components became possible. ${ }^{2}$ Furthermore, this technique is favorable in terms of keyhole stability and also from mechanical point of view especially when regarding residual stresses.
In full-penetration welding mode of steel plates above $15 \mathrm{~mm}$ thickness, weld bead sagging or even a dropout of molten material can occur due to the dominance of the hydrostatic pressure compared to balancing surface tension forces. Conventionally, weld bead backing systems are required which include the need to be removed after welding costly and which can even disturb the welding process by the interference of the keyhole degassing at the root side of the weld.

High power laser beam welding allows for an electromagnetic manipulation of the process. In previous experiments and numerical simulations for austenitic stainless steel 


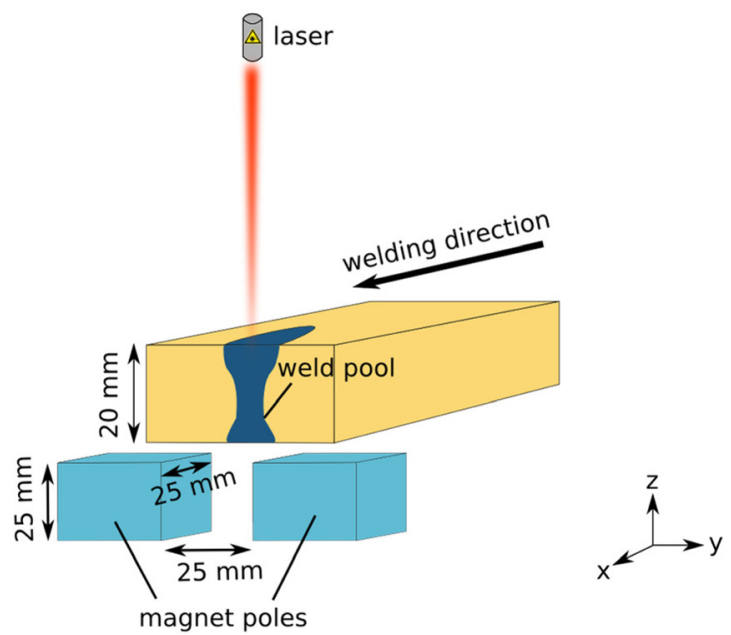

FIG. 1. Sketch of the electromagnetic weld pool support taken from Ref. 6.

and aluminum, ${ }^{3-7}$ it was shown that oscillating magnetic fields below the weld specimen perpendicular to the welding direction can induce Lorentz forces in the melt that are able to balance the hydrostatic pressure in the melt contactless by the interaction of the externally applied magnetic field $\boldsymbol{B}$ with the induced eddy currents $\boldsymbol{j}$. The resulting timeaveraged Lorentz force

$$
\boldsymbol{F}_{\boldsymbol{L}}=\langle\boldsymbol{j} \times \boldsymbol{B}\rangle
$$

is directed mainly in vertical direction. A sketch of the position of the AC magnet below the weld specimen can be seen in Fig. 1.

The Lorentz forces due to an oscillating magnetic field are concentrated within the skin depth $\delta$ of the applied magnetic field

$$
\delta=(\pi \mu \sigma f)^{-0.5}
$$

where $\mu, \sigma$, and $f$ are the magnetic permeability, electrical conductivity, and the oscillation frequency. When reaching the skin depth of a material, the magnetic flux density has decreased by a factor of 1/e (around 0.37) compared to its original value.

In several welding applications relevant to special safety restrictions, e.g., pipelines in protected areas, chemical reactors or even containers for nuclear waste, a safe and reliable welding process is especially important. For the abovementioned applications, duplex stainless steel is often used due to its combination of favorable corrosion resistance and mechanical strength. ${ }^{8}$ These steel grades have physical properties in between austenitic and ferritic steels. During welding, the treatment of the magnetic properties in duplex steels needs to be handled with care as there is a coexistence of regions with and without ferritic properties due to the process temperatures being above the Curie temperature, see Fig. 2 .

Thus, the magnetic field lines bend around the hot region in the vicinity of the weld pool. Furthermore, the nonlinear magnetic hysteresis effects when applying an oscillating magnetic field need to be considered.

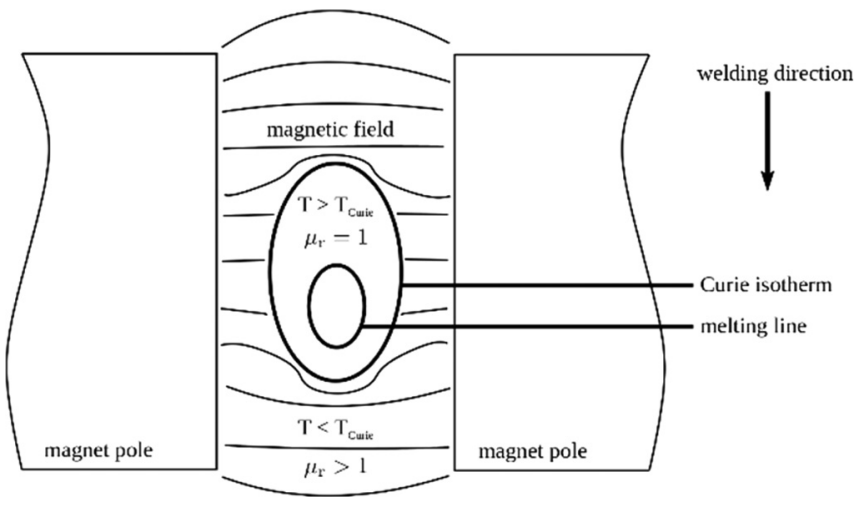

FIG. 2. Schematic magnetic field distribution in duplex stainless steel under consideration of the Curie temperature.

\section{NUMERICAL MODELING}

The numerical investigation of the complete inductive weld pool support process consists of a steady-state fluidthermal simulation coupled to a frequency-domain calculation of the electromagnetic field quantities. This approach allows for a calculation of all involved physical quantities with comparable effort in contrast to a transient simulation with time scales of the electromagnetic fields being much smaller than for the heat transfer. The partial differential equations for the heat transport as well as for the conservation of mass and momentum were solved iteratively. This solution in terms of temperature and velocities was then taken as the reference solution and coupled unidirectional to the Maxwell equations. The formula apparatus for the nonisothermal fluid dynamics calculation routine is fully described in Ref. 7. Marangoni flow stress, natural convection, and latent heat of fusion were considered. This model is referred to as process model.

In order to simulate the electromagnetic weld support for duplex stainless steel AISI 2205, its nonlinear hysteresis properties must be considered. The model of Jiles and Atherton (JAM) was adapted according to Ref. 9 to describe the magnetic hysteresis

$$
\begin{aligned}
& M=M_{\mathrm{irr}}+M_{\mathrm{rev}}, \\
& M_{\mathrm{rev}}=c\left(M_{\mathrm{an}}-M_{\mathrm{irr}}\right),
\end{aligned}
$$

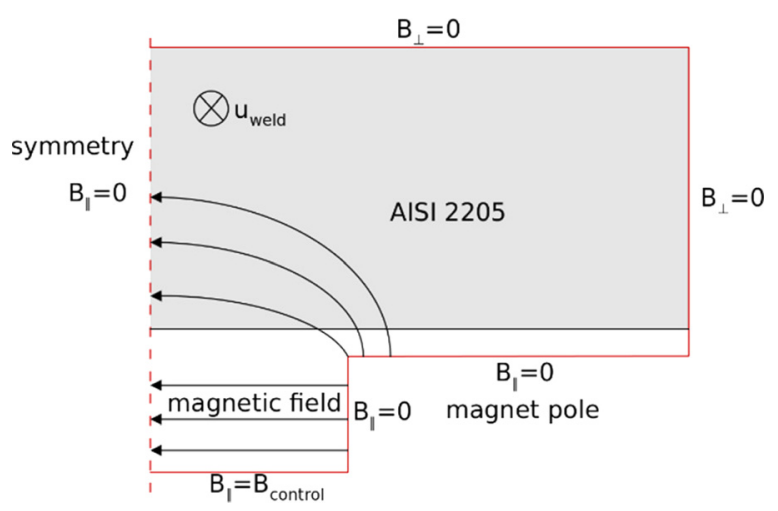

FIG. 3. Transient 2D model for the calculation of the magnetic hysteresis model. 


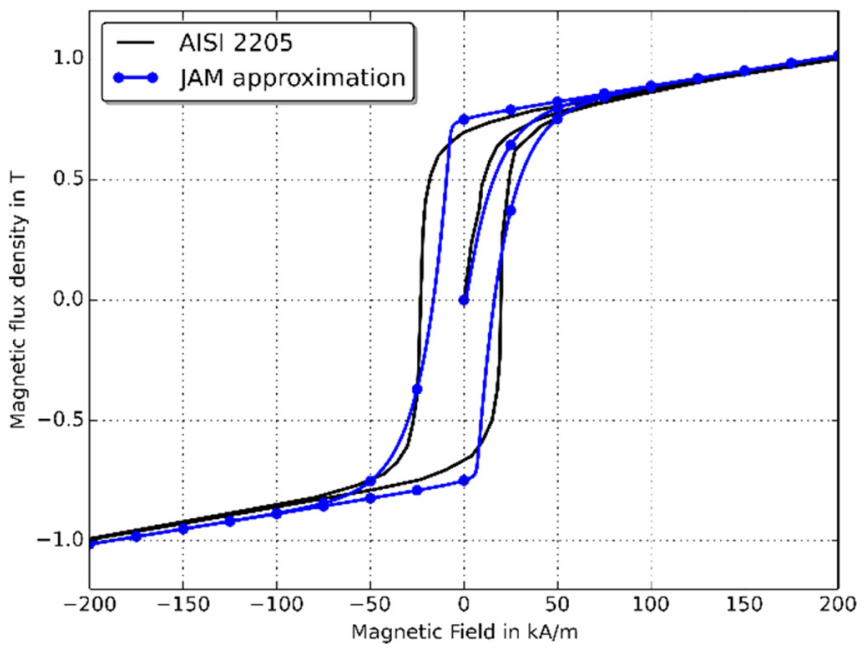

FIG. 4. Magnetic hysteresis for duplex stainless steel taken from Ref. 11 and its calculated approximation for the Jiles-Atherton model.

$$
\begin{aligned}
& M_{\mathrm{an}}=M_{\mathrm{s}}\left[\cot \frac{H_{e}}{a}-\frac{a}{H_{e}}\right], \\
& H_{e}=H+\alpha M, \\
& \frac{\mathrm{d} M_{\mathrm{irr}}}{\mathrm{d} H}=\frac{M_{\mathrm{an}}-M_{\mathrm{irr}}}{\frac{\delta k}{\mu_{0}}-\alpha\left(M_{\mathrm{an}}-M_{\mathrm{irr}}\right)} .
\end{aligned}
$$

Here, the magnetization $M$ was divided into irreversible $M_{\mathrm{irr}}$ and reversible parts $M_{\text {rev }} . M_{\text {an }}$ is the anhysteretic magnetization curve and $H_{e}$ is the effective magnetic field. The model describes the complex magnetic behavior with five parameters. These parameters can be derived from the hysteresis curve with the method of least squares. ${ }^{10}$ Considering the numerical costs, running the JAM simulation transiently is not well suited for a 3D process simulation. Therefore, we developed a 2D model cutting a plane of the process model at the laser axis position perpendicular to the weld direction, see Fig. 3. Thus, three-dimensional effects of the electromagnetic fields, e.g., due to the magnet pole geometry or the temperature dependent electrical conductivity were not considered.

Figure 4 shows the comparison between the hysteresis loop taken from the literature ${ }^{11}$ and the results from the model. The calculated parameters for the JAM are shown in Table I.

Another possibility to include hysteresis effects in the simulations is by the use of a complex permeability ${ }^{12}$

$$
\mu_{r}=\mu_{r}^{\prime}+i \mu_{r}^{\prime \prime}
$$

Hereby, the hysteresis loop was approximated by an elliptic curve in the $\boldsymbol{H}-\boldsymbol{B}$ space. Hence, magnetic saturation effects were not included in the model which was not significant for the magnetic flux densities used in this investigation. The complex permeability is a good compromise between

TABLE I. Results of the parameter calculation for the JAM.

\begin{tabular}{lcccc}
\hline \hline$M_{s}$ & $k$ & $a$ & $\alpha$ & $c$ \\
\hline $610 \mathrm{kA} / \mathrm{m}$ & $24.2 \mathrm{kA} / \mathrm{m}$ & $834.4 \mathrm{~A} / \mathrm{m}$ & 0.0063 & 0.0001 \\
\hline \hline
\end{tabular}

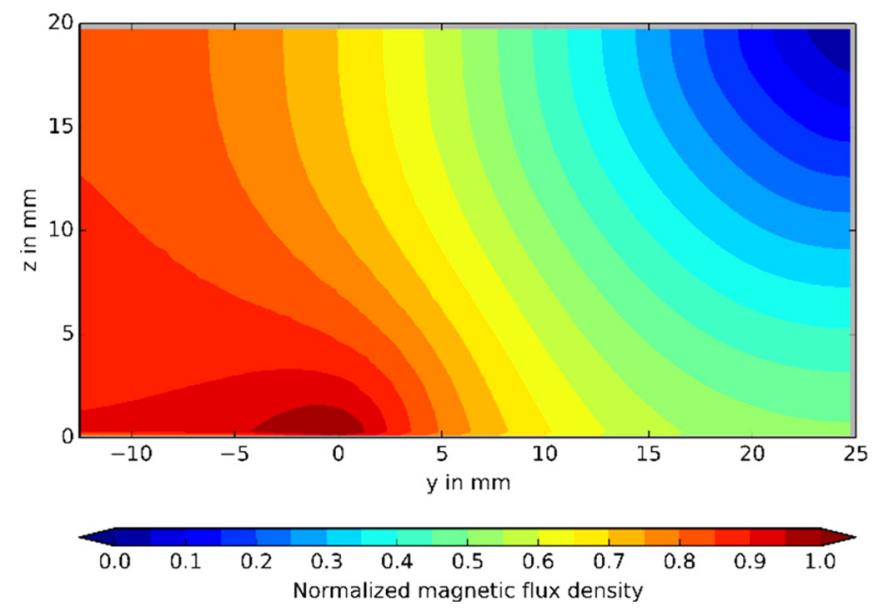

FIG. 5. Exemplary normalized magnetic flux density distribution from the JAM at an oscillation frequency of $3 \mathrm{kHz}$.

complexity and accuracy and can also be implemented in steady-state time-harmonic solvers. The link between the JAM and the complex permeability model can be done by the need for equality of the total magnetic hysteresis losses in the calculation domain (see Fig. 3). The time-averaged magnetic hysteresis losses $P_{\text {Loss }}$ per unit volume read

$$
P_{\text {LOSS }}=\frac{1}{t} \int_{0}^{t}\left(\boldsymbol{H} \cdot \frac{\partial \boldsymbol{B}}{\partial t}\right) d t .
$$

In the end, the coefficients for the complex permeability can be derived from

$$
\begin{aligned}
& \mu_{r}^{\prime \prime}=\frac{1}{2 \pi f \mu_{0}} \frac{\int P_{\mathrm{Loss}} d V}{\int \boldsymbol{H}_{\mathrm{RMS}} \cdot \boldsymbol{H}_{\mathrm{RMS}} d V}, \\
& \mu_{r}^{\prime}=\operatorname{Re}\left\{\sqrt{\frac{\int \boldsymbol{B}_{\mathrm{RMS}} \cdot \boldsymbol{B}_{\mathrm{RMS}} d V}{\mu_{0}^{2} \int \boldsymbol{H}_{\mathrm{RMS}} \cdot \boldsymbol{H}_{\mathrm{RMS}} d V}-\left(\mu_{r}^{\prime \prime}\right)^{2}}\right\} .
\end{aligned}
$$

This yields for the complex permeability

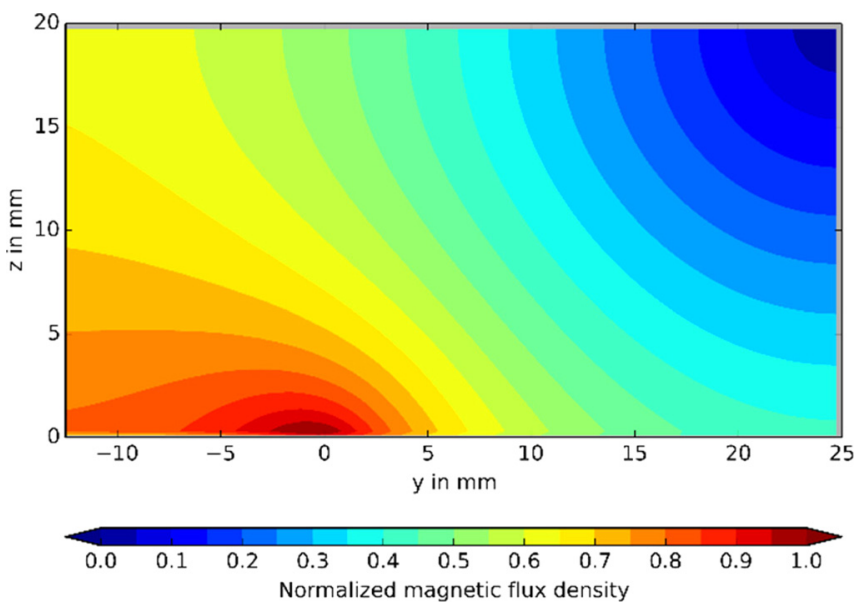

FIG. 6. Exemplary normalized magnetic flux density distribution from the complex permeability model at an oscillation frequency of $3 \mathrm{kHz}$. 


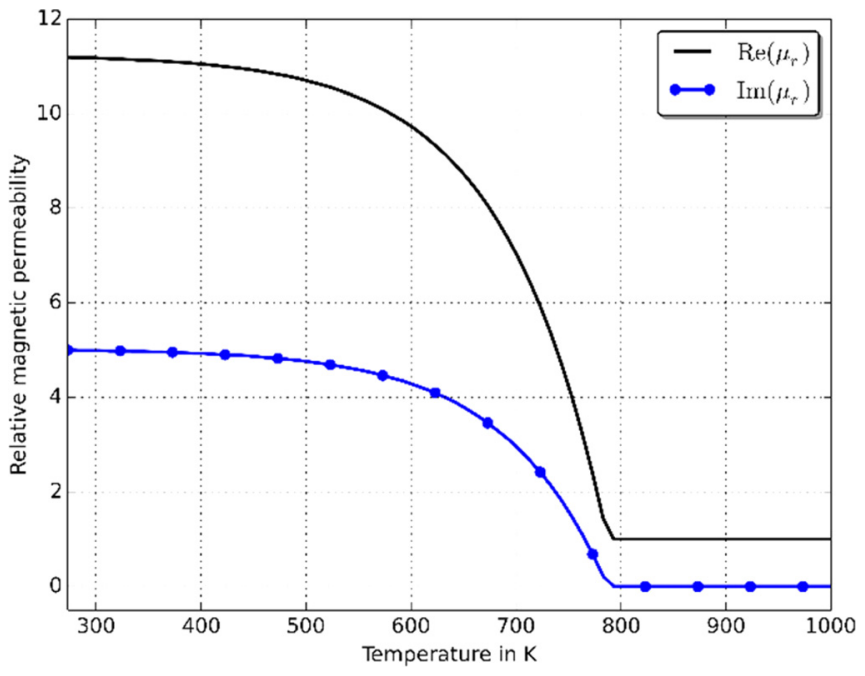

FIG. 7. Temperature-dependent real and imaginary part of the complex magnetic permeability.

TABLE II. Material properties of duplex stainless steel at melt temperature (Ref. 13).

\begin{tabular}{lc}
\hline \hline Material parameter & AISI 2205 \\
\hline Solidus temperature & $1589 \mathrm{~K}$ \\
Liquidus temperature & $1715 \mathrm{~K}$ \\
Evaporation temperature & $3000 \mathrm{~K}$ \\
Curie temperature & $787 \mathrm{~K}$ \\
Mass density & $7200 \mathrm{~kg} / \mathrm{m}^{3}$ \\
Heat capacity in solid & $419 \mathrm{~J} / \mathrm{kg} \mathrm{K}$ \\
Heat capacity in liquid & $808 \mathrm{~J} / \mathrm{kg} \mathrm{K}$ \\
Thermal conductivity in solid & $18.8 \mathrm{~W} / \mathrm{m} \mathrm{K}$ \\
Thermal conductivity in liquid & $41.8 \mathrm{~W} / \mathrm{m} \mathrm{K}$ \\
Latent heat of fusion & $270 \times 10^{3} \mathrm{~J} / \mathrm{kg}$ \\
Dynamic viscosity & $8.5 \times 10^{-3} \mathrm{~Pa} \mathrm{~s}$ \\
Coefficient of thermal expansion & $1 \times 10^{-5} 1 / \mathrm{K}$ \\
Surface tension coefficient & $-4.29 \times 10^{-4} \mathrm{~N} / \mathrm{m} \mathrm{K}$ \\
\hline \hline
\end{tabular}

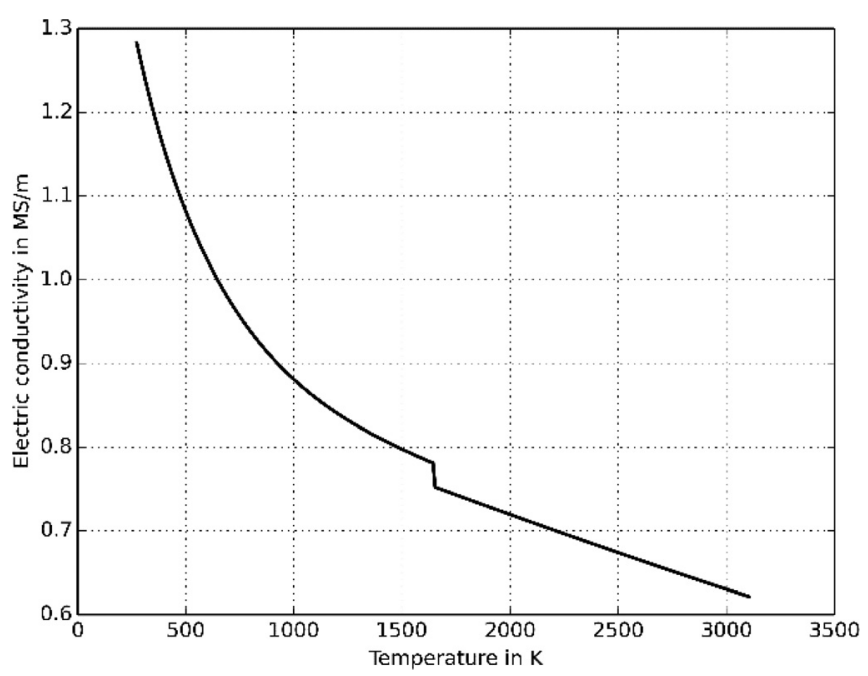

FIG. 8. Temperature-dependent electric conductivity.
TABLE III. Parameters of the numerical model.

\begin{tabular}{lc}
\hline \hline Plate thickness & $20 \mathrm{~mm}$ \\
Welding velocity & $0.6 \mathrm{~m} / \mathrm{min}$ \\
Magnet pole width and height & $25 \mathrm{~mm}$ \\
Distance magnet/workpiece & $2 \mathrm{~mm}$ \\
Distance magnet poles & $25 \mathrm{~mm}$ \\
\hline \hline
\end{tabular}

$$
\mu_{r}=10.89+i 5.23 .
$$

That value was derived for an oscillation frequency of 3 $\mathrm{kHz}$. It was found that the differences in $\mu_{r}$ for typical oscillation frequencies used for an inductive weld support between 1 and $10 \mathrm{kHz}$ could be neglected.

The differences in the peak magnetic flux densities for the JAM and the complex permeability model in the configuration shown in Fig. 3 can be seen in Figs. 5 and 6. The maximum of the magnetic flux density is located above the air gap between the magnet poles in both cases. Qualitatively, both models agree very well. For the process simulations, only the complex permeability model calibrated with the JAM was considered.

The magnetic permeability was included in the $3 \mathrm{D}$ process model temperature-dependent to consider the effects caused by the Curie temperature, above which the magnetic behavior becomes ideal nonferromagnetic, see Fig. 7. The implemented material model can be seen in Table II as well as in Fig. 8. Geometrical details about the calculation domains of the process model and boundary conditions can be found in Ref. 7 as well as in Table III.

In the experiments, the magnetic field cannot be measured directly. Therefore, a cold test model (without the heating due to the laser beam) was set up to compare the simulated magnetic fields with experimental values measured by a Hall probe before conducting the simulations for the process model of the weld pool support, see Fig. 9. Three different configurations were investigated to test the simulation model:

(a) Magnetic properties of pure austenitic steel, i.e., the magnetic permeability was set to unity.

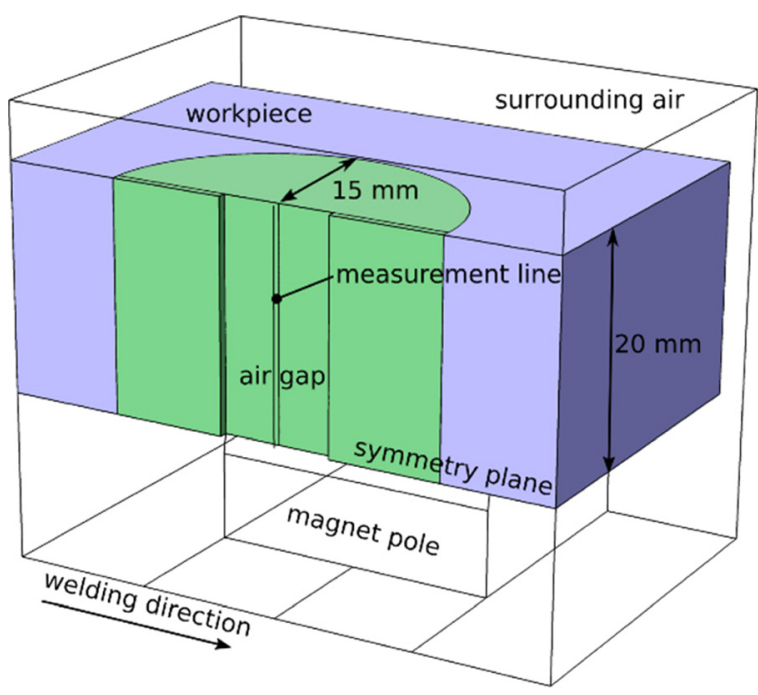

FIG. 9. Cold test model. 


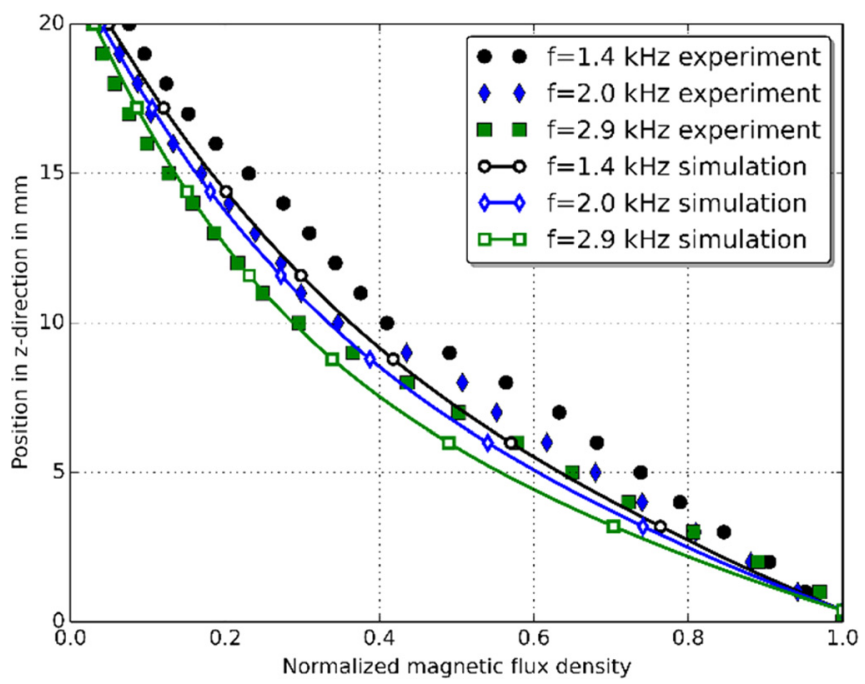

FIG. 10. Results of the cold test measurements for the configuration with austenitic stainless steel.

(b) Magnetic properties of pure duplex stainless steel, i.e., magnetic losses were accounted.

(c) A mixed model with austenitic stainless steel (nonferromagnetic, green region in Fig. 9) surrounded by duplex stainless steel (blue) to account for the demagnetization that occurs during welding due to exceeding the Curie temperature.

The results of the assisting welding experiments of duplex stainless steel AISI 2205 can be found in an accompanying ICALEO publication. ${ }^{14}$

\section{RESULTS AND DISCUSSION}

\section{A. Cold test model}

The results of the cold test simulations compared to accompanying measurements of the magnetic flux density for austenitic stainless steel are shown in Fig. 10. Three different oscillation frequencies between 1.4 and $2.9 \mathrm{kHz}$ were chosen according to the experiences from previous work. ${ }^{7}$ The corresponding theoretical skin depths can be seen in Table IV.

It shows that the simulations can reproduce the expected behavior in the cold material very well. With increasing oscillation frequency, the magnetic flux density decreases with a steeper gradient for an increasing depth into the material. Furthermore, the expected skin depth from Table IV could be confirmed in the simulations as well as in the experiments. The experiments and simulations were repeated for configurations (b) and (c). Slight changes in the oscillation frequency are due to the experimental setup. They were adapted in the simulations as well.

The results of the cold tests for configuration (b) with duplex stainless steel can be seen in Fig. 11. Compared to

TABLE IV. Skin depth in austenitic stainless steel at room temperature.

\begin{tabular}{lccc}
\hline \hline Frequency in $\mathrm{kHz}$ & 2.9 & 2.0 & 1.4 \\
Skin depth in $\mathrm{mm}$ & 8 & 10 & 12 \\
\hline \hline
\end{tabular}

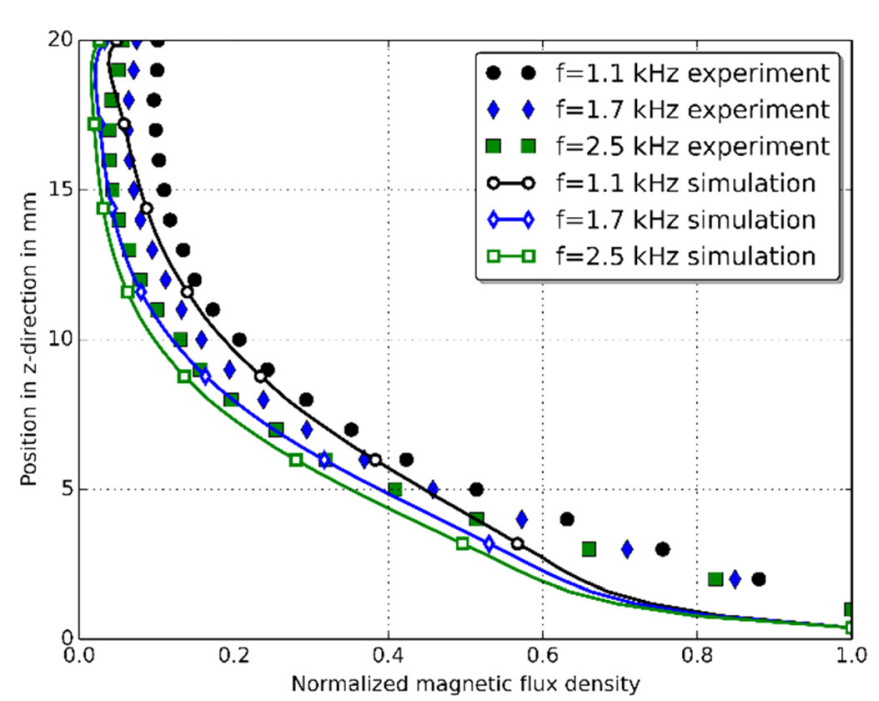

FIG. 11. Results of the cold test measurements for the configuration with duplex stainless steel.

austenitic stainless steel, the skin depth for similar frequencies is smaller associated with a steeper gradient in the bottom region, which is due to the ferromagnetic effects there. Furthermore, the absolute values of the magnetic flux density are higher in configuration (b) compared to (a) for the same conditions due to the relative magnetic permeability being larger unity.

The results of configuration (c)-austenitic material surrounded by duplex material-is shown in Fig. 12. Here, the measured and calculated B curves are comparable to the case with pure austenitic material. The computational results are backed by the experiments very well.

\section{B. Process model}

In the next step, the electromagnetic model for duplex stainless steel, which was calibrated by a series of cold tests, was coupled to a nonisothermal reference solution of the flow field and its associated temperature distribution. Under

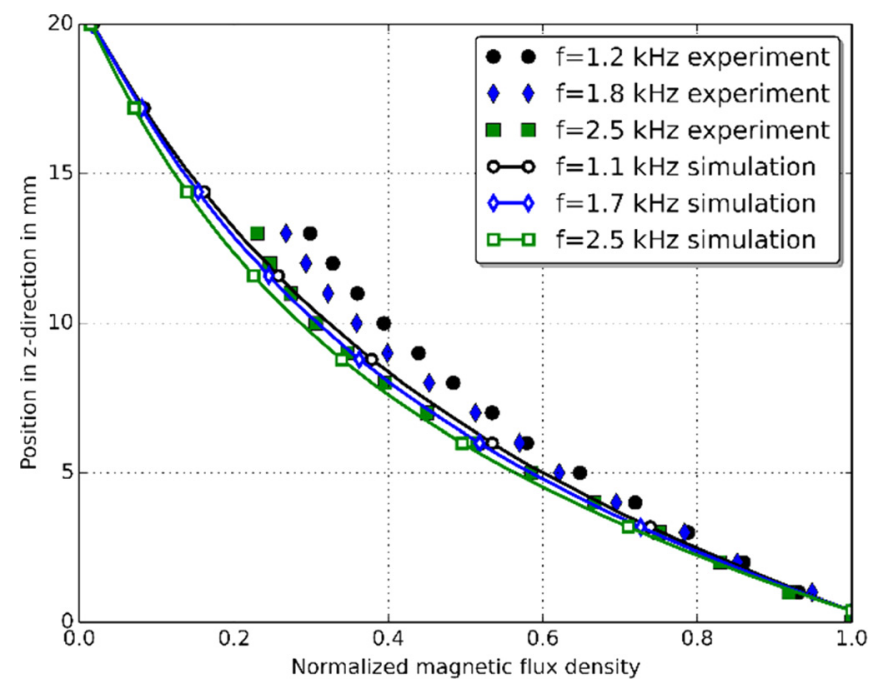

FIG. 12. Results of the cold test measurements for the configuration with austenitic stainless steel (green region in Fig. 9) surrounded by duplex stainless steel (blue). 

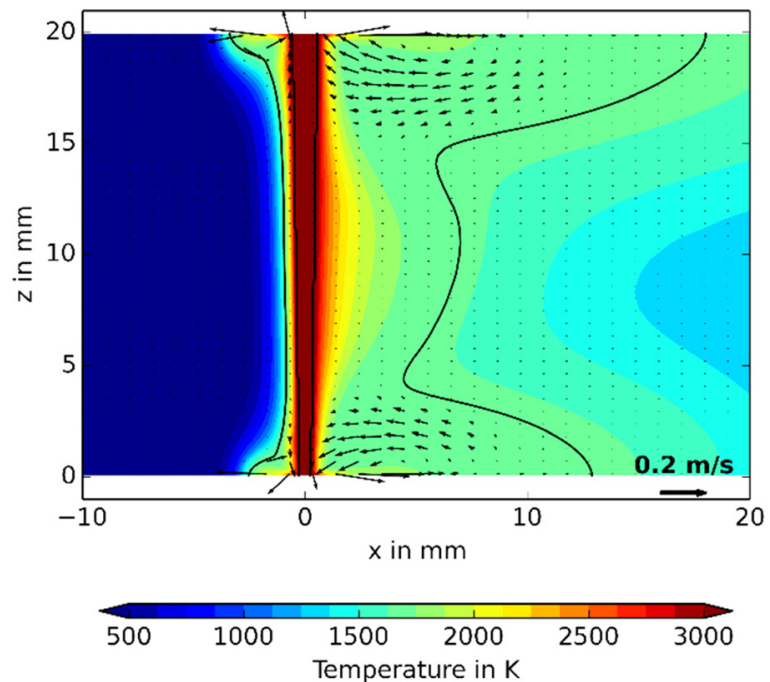

FIG. 13. Temperature distribution as well as velocity vectors in the symmetry plane for the reference case without electromagnetic weld pool support for duplex stainless steel AISI 2205.

the assumption of fixed walls in the simulations, the expected differences in the flow field and the heat distribution in the workpiece are expected to be small enough to be neglected. ${ }^{7}$ Therefore, the numerical costs could be reduced immense by simplifying the whole issue to a unidirectional coupled simulation. The degree of compensation of the hydrostatic pressure in the melt was done by a line integration of the time-averaged vertical component of the Lorentz force along a vertical line in the symmetry plane at a position $2 \mathrm{~mm}$ behind the keyhole

$$
p(z)=p_{\text {ref }}(z)-\int_{Z_{0}}^{z_{\max }}\left\langle F_{L}^{Z}\right\rangle d z .
$$

The results of the reference case in terms of temperature and flow field distributions in the symmetry plane can be seen in Fig. 13.

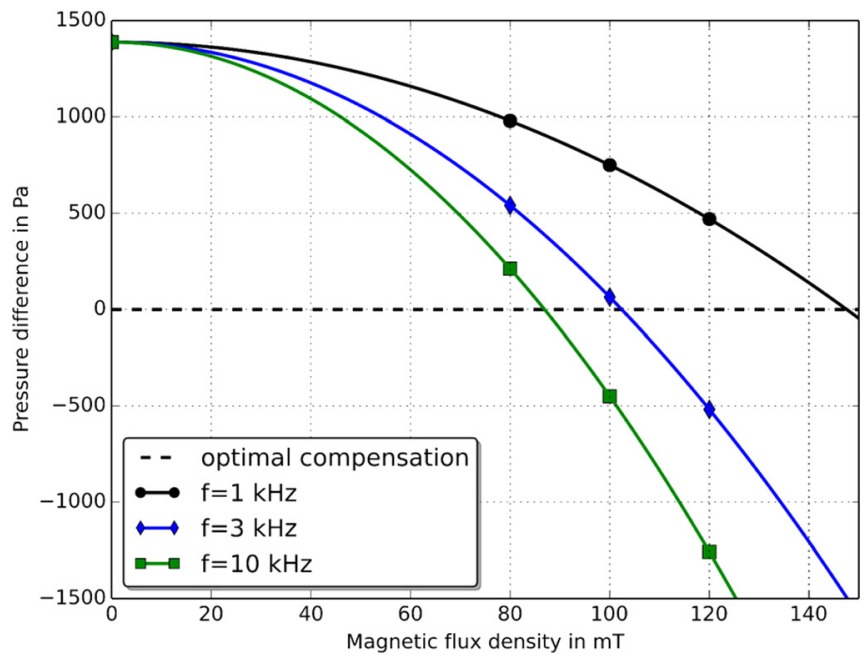

FIG. 14. Simulation results of the electromagnetic compensation of the pressure differences between upper and lower weld bead surfaces for austenitic stainless steel for different oscillation frequencies. Dots indicate simulation results.

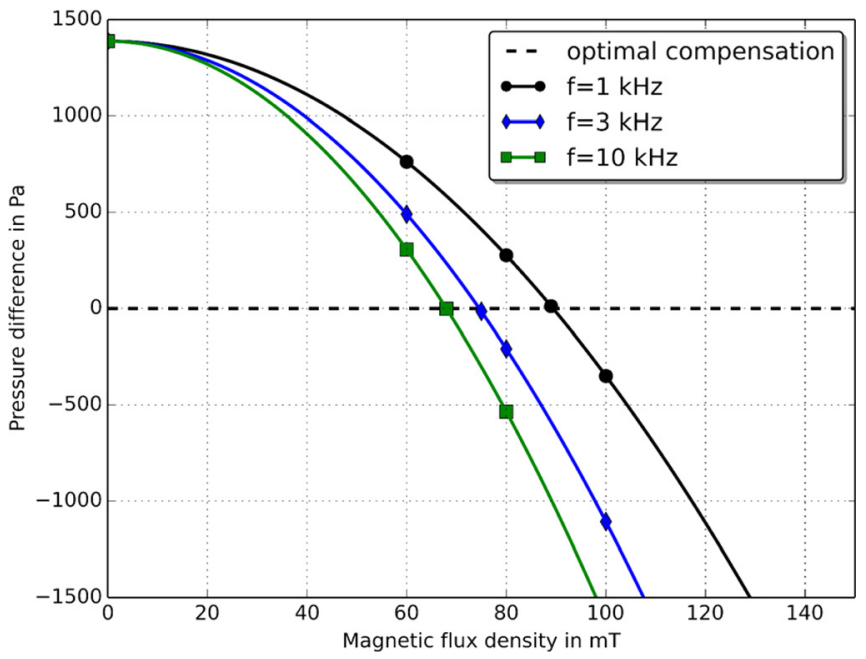

FIG. 15. Simulation results of the electromagnetic compensation of the pressure differences between upper and lower weld bead surfaces for duplex stainless steel for different oscillation frequencies. Dots indicate simulation results.

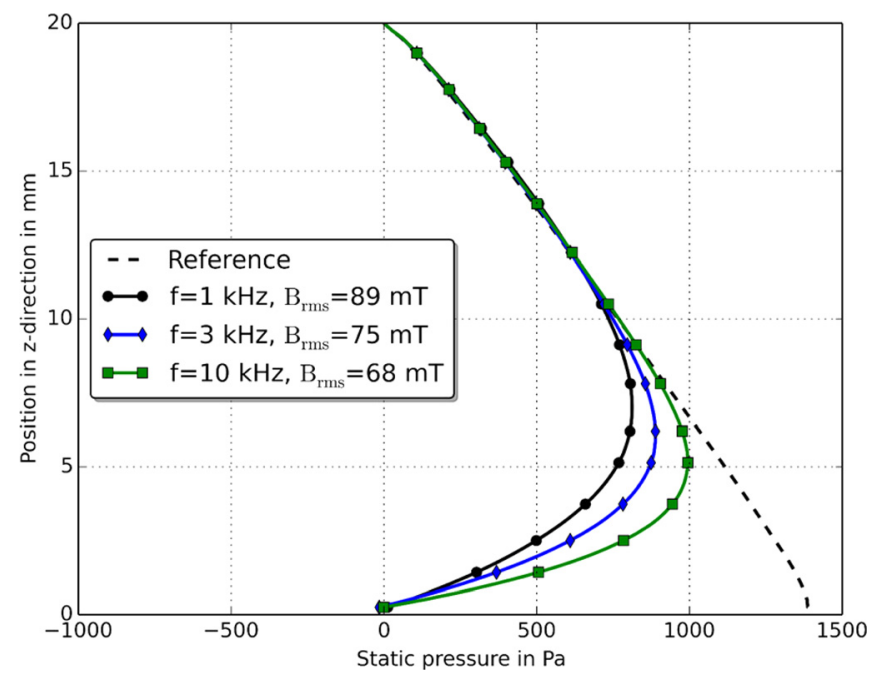

FIG. 16. Simulation results of the pressure distributions in the melt for duplex stainless steel for the optimal cases for each oscillation frequency.

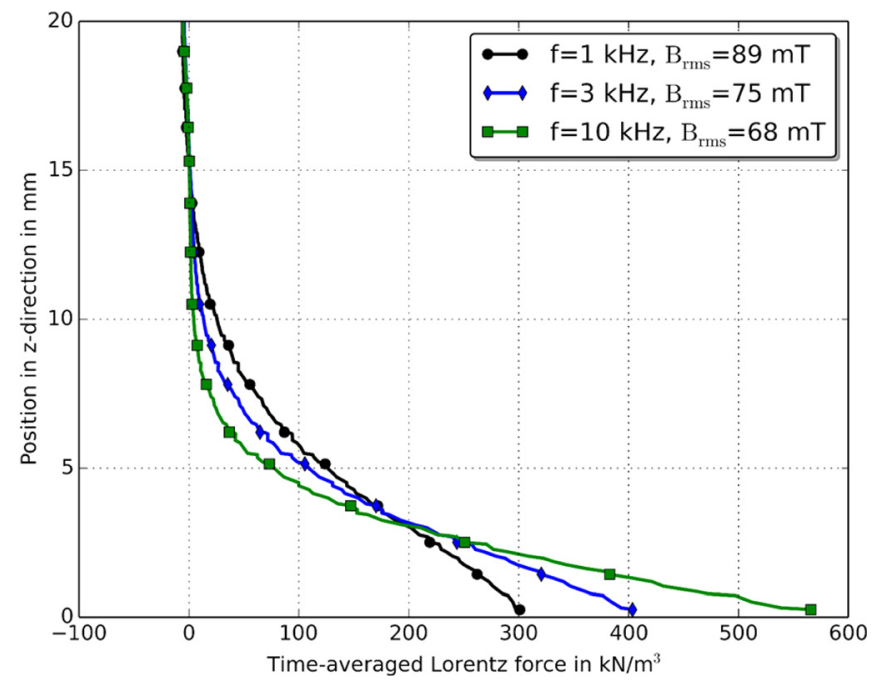

FIG. 17. Simulation results of the vertical Lorentz force component in the melt for duplex stainless steel for the optimal cases for each oscillation frequency. 
austenitic material
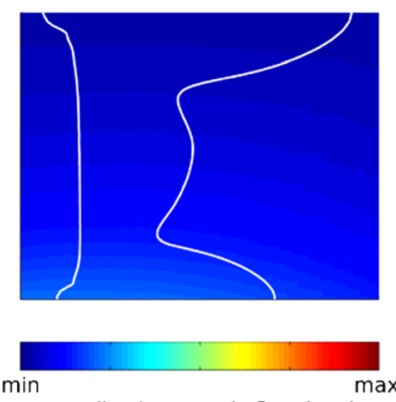

Normalized magnetic flux density
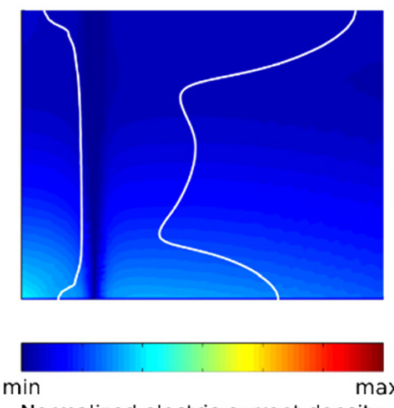

Normalized electric current density
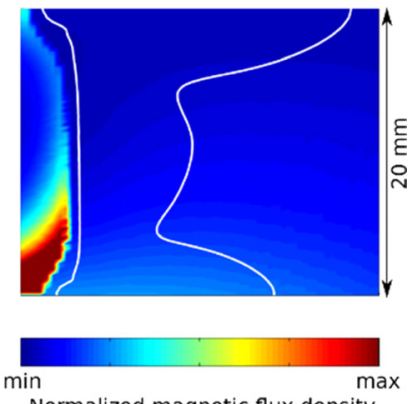

Normalized magnetic flux density

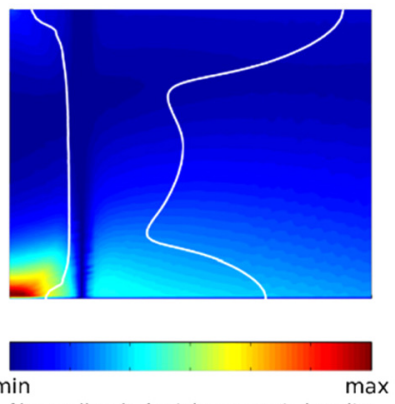

Normalized electric current density duplex material

FIG. 18. Results of the qualitative magnetic flux and electric current density distributions from the computer simulations for austenitic and duplex stainless steel.

Near the free surfaces, large vortices due to Marangoni stresses occur. The flow field in the middle of the weld bead is nearly two-dimensional being directed in the horizontal plane. The temperature distribution is shaped characteristically influenced by the strong convection at the surfaces. In the middle region, where the conduction of heat is less affected by the Marangoni flow, the temperature gradients are smaller.

The results of the simulation for the electromagnetic weld pool support in terms of pressure differences between upper and lower weld bead surfaces for austenitic material as well as duplex stainless steel with adapted complex magnetic

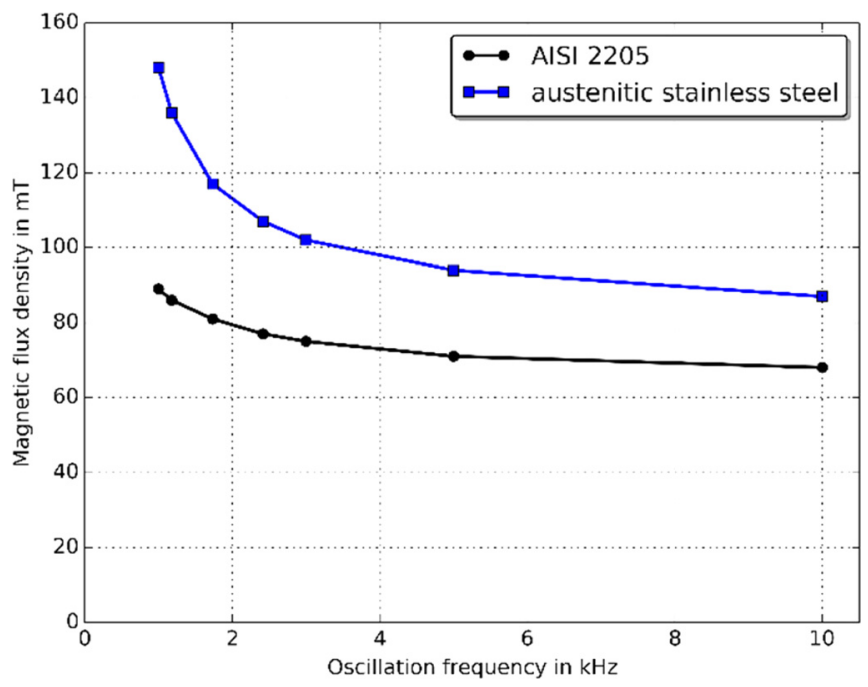

FIG. 19. Numerically predicted optimal magnetic flux densities for a complete compensation of the hydrostatic pressure in $20 \mathrm{~mm}$ thick austenitic and duplex stainless steel.
TABLE V. Comparison of the accumulated electromagnetic power (magnetic losses and resistive losses in the specimen) from the simulations and the experimentally measured AC power for duplex stainless steel AISI 2205.

\begin{tabular}{lcc}
\hline \hline & Frequency & AC power \\
\hline Sim. $20 \mathrm{~mm}$ & $1 \mathrm{kHz}$ & $1.0 \mathrm{~kW}$ \\
& $3 \mathrm{kHz}$ & $1.4 \mathrm{~kW}$ \\
& $10 \mathrm{kHz}$ & $2.3 \mathrm{~kW}$ \\
Exp. $15 \mathrm{~mm}$ & $1.2 \mathrm{kHz}$ & $1.6 \mathrm{~kW}$ \\
& $1.7 \mathrm{kHz}$ & $1.6 \mathrm{~kW}$ \\
& $2.4 \mathrm{kHz}$ & $1.6 \mathrm{~kW}$ \\
Exp. $20 \mathrm{~mm}$ & $1.8 \mathrm{kHz}$ & $1.7 \mathrm{~kW}$ \\
& $2.5 \mathrm{kHz}$ & $2.4 \mathrm{~kW}$ \\
\hline
\end{tabular}

permeability model to account for the magnetic hysteresis losses are shown in Figs. 14 and 15. The value for a magnetic flux density of 0 corresponds to the hydrostatic pressure value at the bottom surface of the reference case. The given value of the magnetic flux densities refers to the applied boundary condition $\mathrm{B}_{\text {control }}$ for the magnetic field between the magnet poles in accordance to the cold tests conducted previously. It shows that the magnetic flux density needed for an optimal compensation of the hydrostatic pressure in the melt decreases with increasing oscillation frequency. This is in accordance to previous investigations. ${ }^{7}$

The comparison between both materials reveals that the optimal magnetic flux density for a given frequency and plate thickness is smaller for the duplex material. The distributions of the simulated optimal cases for the complete compensation of the hydrostatic pressure and the corresponding Lorentz force distributions for duplex stainless steel are shown in Figs. 16 and 17 for varying oscillation frequencies and corresponding skin depths. The reference case in Fig. 16 shows the linear increase of the hydrostatic pressure in the melt.

The changes in the required magnetic flux density for an optimal compensation between austenitic and duplex stainless steel lies in the demagnetization effect of the duplex material when being heated above the Curie temperature. In the case of austenitic material, the magnetic flux density and the electric current density are almost homogeneously distributed in the weld pool, still respecting the effects due to the finite size of the magnet poles and the electric conductivity in

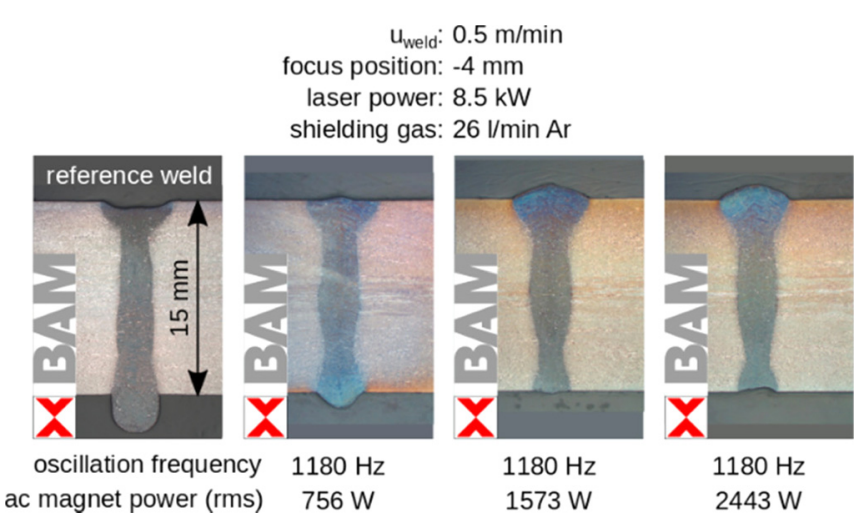

FIG. 20. Experimental macrographs of $15 \mathrm{~mm}$ thick welds of duplex stainless steel AISI 2205 with increasing electromagnetic power of the weld support system. 


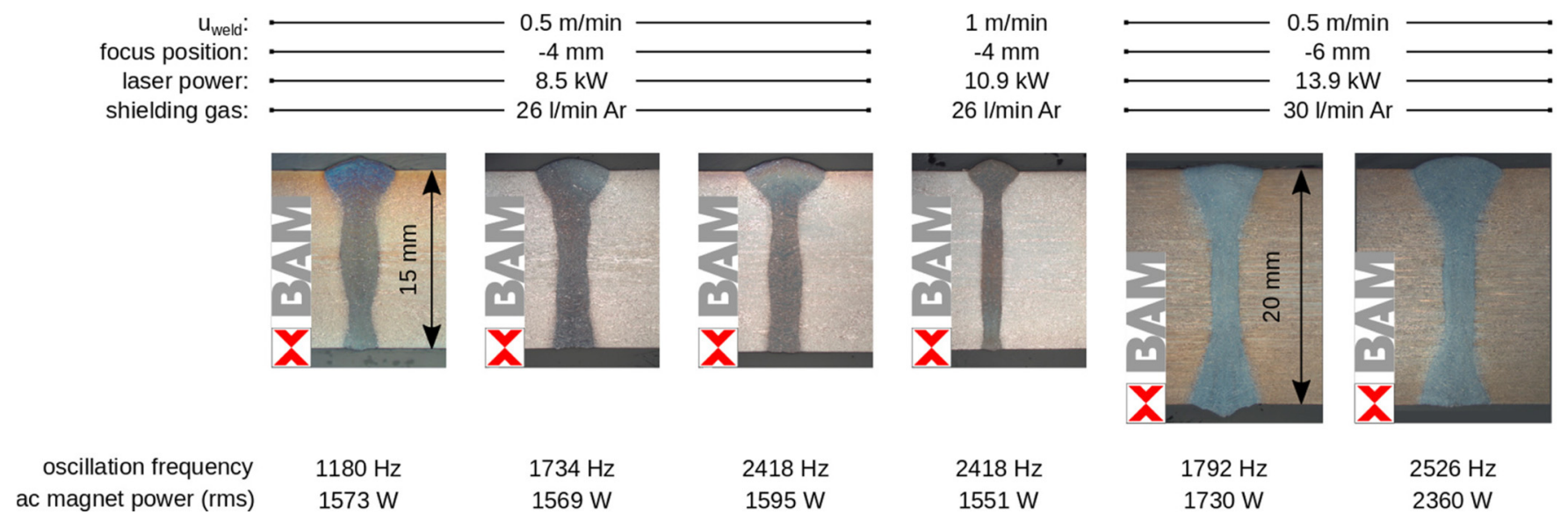

FIG. 21. Optimal compensated experimental macrographs of 15 and $20 \mathrm{~mm}$ thick welds of duplex stainless steel AISI 2205.

the keyhole being different from the surrounding material, see Fig. 18. In the case of duplex material, the magnetic flux density in front of the weld pool is higher compared to the austenitic case as the temperature there lies below the Curie temperature. Thus, the magnetic permeability is large compared to the region around the weld pool that shows nonferromagnetic behavior.

In the same way, the induced electric current density is very high in front of the weld pool for duplex stainless steel. As the region being heated above the Curie temperature around the weld pool remains small and the distributions of the magnetic field and the electric current density must be continuous, these quantities are somewhat increased also in the liquid zone compared to austenitic material. In the end, the resulting Lorentz force is higher as well and the magnetic flux density needed for an optimal compensation of the hydrostatic pressure in the melt becomes smaller, see Fig. 19.

The magnetic flux density cannot be measured directly during the execution of the experiments due to the laser radiation. Therefore, only measured values of the magnetic flux density before welding are available. For duplex stainless steel, there are strong changes in $\boldsymbol{B}$ due to the nonlinear relation to the magnetic field $\boldsymbol{H}$ at the interface between air and the workpiece. During the welding process, the magnetic flux density changes significantly due to the heating of the material above the Curie temperature and corresponding demagnetization. Therefore, a comparison between the experiments and the simulations can only be done in terms of electromagnetic power, see the values for the optimized cases in Table V. The AC power from the experiments refers to the product of the rms values of the measured voltages and currents in the magnet circuit, whereas the values in the simulations refer only to resistive losses and magnetic hysteresis losses in the workpiece.

The comparison shows a good agreement between experiments and simulations, especially when regarding the numerical simplifications of the magnetic hysteresis represented elliptically. Exemplary experimental results are shown in Figs. 20 and Figs. 21. The experiments for 15 and $20 \mathrm{~mm}$ thick AISI 2205 were done with a $20 \mathrm{~kW}$ Yb:YAG fiber laser from IPG Photonics and a TRUMPF TruDisk 16002 thin disk laser, respectively. An analysis of the experimental results obtained is published in an accompanying paper. ${ }^{14}$

\section{SUMMARY}

This paper describes a numerical and experimental investigation of a contactless electromagnetic weld pool support system for duplex stainless steel AISI 2205.

The simulations as well as the experiments show the good applicability of this technology to the single-pass fullpenetration high power laser beam welding of steels with ferromagnetic properties. It was found that an AC power of less than $2.5 \mathrm{~kW}$ at oscillation frequencies between 1 and $10 \mathrm{kHz}$ was sufficient to compensate for the hydrostatic pressure of $20 \mathrm{~mm}$ thick material. This was also backed by experiments conducted for material thicknesses of 15 and $20 \mathrm{~mm}$.

In the future, the electromagnetic weld pool support system will be tested with the important material class of ferromagnetic steels.

\section{ACKNOWLEDGMENTS}

This work was supported by the DFG (Deutsche Forschungsgemeinschaft, Bonn, Germany) under Grant No. DFG GU 1211/2-2.

${ }^{1}$ J. F. Ready and D. F. Farson, LIA Handbook of Laser Materials Processing (Springer, Berlin, 2001).

${ }^{2}$ F. Vollertsen, S. Grünenwald, M. Rethmeier, A. Gumenyuk, U. Reisgen, and S. Olschok, "Welding thick steel plates with fibre lasers and GMAW," Weld. World 54, R62-R70 (2010).

${ }^{3}$ L. P. Jones, P. Aubert, V. Avilov, F. Coste, W. Daenner, T. Jokinen, K. R. Nightingale, and M. Wykes, "Towards advanced welding methods for the ITER vacuum vessel sectors," Fusion Eng. Des. 69, 215-220 (2003).

${ }^{4}$ V. Avilov, A. Gumenyuk, M. Lammers, and M. Rethmeier, "PA position full penetration high power laser beam welding of up to $30 \mathrm{~mm}$ thick $\mathrm{AlMg}_{3}$ plates using electromagnetic weld pool support," Sci. Technol. Weld. Joining 17, 128-133 (2012).

${ }^{5}$ M. Bachmann, V. Avilov, A. Gumenyuk, and M. Rethmeier, "Numerical simulation of full-penetration laser beam welding of thick aluminium plates with inductive support," J. Phys. D: Appl. Phys. 45, 035201 (2012).

${ }^{6} \mathrm{M}$. Bachmann, V. Avilov, A. Gumenyuk, and M. Rethmeier, "numerical simulation of electromagnetic melt control systems in high power laser beam welding," in Proceedings of the ICALEO 2013, 32nd International Congress on Applications of Lasers \& Electro-Optics, Miami, USA (2013), pp. 50-59. 
${ }^{7}$ M. Bachmann, V. Avilov, A. Gumenyuk, and M. Rethmeier, "Experimental and numerical investigation of an electromagnetic weld pool support system for high power laser beam welding of austenitic stainless steel," J. Mater. Process. Technol. 214, 578-591 (2014).

${ }^{8}$ A. Backhouse, Welding of Austenitic \& Duplex Stainless Steels-Overview (Outokumpu Stainless, 2011); available at www.scottish-enterprise.com/ media/se/resources/documents/wxyz/welding-of-austenitic-and-duplexstainless-steels-overview-backhouse-outokumpu.pdf.

${ }^{9}$ D. C. Jiles and D. L. Atherton, "Theory of ferromagnetic hysteresis," J. Magn. Magn. Mater. 61, 48-60 (1986).

${ }^{10}$ N. C. Pop and O. F. Caltun, "Jiles-Atherton magnetic hysteresis parameters identification," Acta Phys. Pol., A 120, 491-496 (2011).

${ }^{11}$ S. S. M. Tavares, M. R. Da Silva, and J. M. Neto, "Magnetic property changes during embrittlement of a duplex stainless steel," J. Alloy. Compd. 313, 168-173 (2000).

${ }^{12}$ COMSOL Multiphysics, Modeling Hysteresis Effects, 2008.

${ }^{13}$ T. A. Palmer, J. W. Elmer, and S. S. Babu, "Observations of ferrite/austenite transforma-tions in the heat affected zone of 2205 duplex stainless steel spot welds using time resolved X-ray diffraction," Mater. Sci. Eng. A 374, 307-321 (2004).

${ }^{14}$ V. Avilov, A. Fritzsche, M. Bachmann, A. Gumenyuk, and M. Rethmeier, "Full penetration laser beam welding of thick plates of duplex steel with electromagnetic weld pool support," in Proceedings of the ICALEO 2015, 34th International Congress on Applications of Lasers and Electro-Optics, Atlanta, USA (2015).

\section{Meet the Authors}

Dr.-Ing. Marcel Bachmann, born 1984 in Berlin, is with the BAM Federal Institute for Materials Research and Testing in Berlin, Germany, in the "Welding Technology" department since 2009. He received his diploma from the Technical University Berlin in Physical Engineering and his
$\mathrm{Ph}$.D. for numerical investigations of electromagnetically assisted high power laser beam welding processes. Currently, he is working on several projects involving numerical simulations in welding processes.

Mr. Kunze was with the BAM Federal Institute for Materials Research and Testing in the "Welding Technology" department. Currently, he is working on his master thesis in Information Technology in Mechanical Engineering to be received from the Technical University Berlin. His thesis deals with multiphysical numerical simulations in laser beam welding.

Dr. rer. nat. Vjaceslav Avilov is with the Institute of Machine Tools and Factory Management at the Technical University Berlin. Before, he was with the BAM Federal Institute for Materials Research and Testing. His current activities include experimental work on electromagneticassisted high power laser beam as well as electron beam welding processes.

Professor Dr.-Ing. Michael Rethmeier is with the BAM Federal Institute for Materials Research and Testing. He is the head of the "Welding Technology" division. He is also heading the "Chair of Safety of Joined Components" at the Institute of Machine Tools and Factory Management, Technical University Berlin. Present research topics include amongst others innovative arc welding processes, high power laser beam welding and numerical simulations in various welding processes. 